\title{
A RELEITURA DAS CONEXÕES ENTRE O DIREITO E A MORAL: O PÓSPOSITIVISMO COMO MARCO FILOSÓFICO PARA O NEOCONSTITUCIONALISMO
}

\author{
REREADING THE CONNECTIONS OF LAW AND MORAL: POST-POSITIVISM \\ AS REFERENCE FOR PHILOSOPHICAL NEOCONSTITUTIONALISM
}

\author{
Diogo Oliveira Muniz Caldas ${ }^{1}$ \\ Renata Souto Perdigão Granha
}

\section{RESUMO}

Na prática dos operadores do direito, tem sido recorrente o fundamento de que normas abertas, princípios e regras devem ser aplicados por meio da ponderação de valores. Entretanto, ainda se observa uma postura demasiadamente positivista de cunho exegético, rechaçando aspectos axiológicos, o que demonstra uma prática, às vezes antagônica, que oscila entre o discurso póspositivista e o tradicional positivismo. A proposta do presente estudo versa integrar a discussão entre moral e direito, nas teorias jusnaturalistas, juspositivistas e pós-positivistas, para melhor compreensão da Teoria do Direito, no panorama atual.

Palavras-chaves: Moral e Direito; Juspositivismo; Pós-positivismo; Neoconstitucionalismo

\begin{abstract}
In practice of law professionals, it has been a recurring basis that the open standards, principles and rules should be applied by the weighting values. However, still observed an excessively positivist stance exegetical nature, rejecting axiological aspects, which shows a practical, sometimes antagonistic, ranging from post-positivist discourse and traditional positivism. The purpose of this study integrate discussion between morality and law, the natural law, juspositivistas theories and post-positivist, for better understanding of legal theory, in the current scenario.
\end{abstract}

Keywords: Moral and Law; Juspositivism; Postpositivism; Neoconstitutionalism

\footnotetext{
${ }^{1}$ Doutor em Direito pela Universidade Veiga de Almeida - UVA, Rio de Janeiro, (Brasil). Professor do Curso de Direito da Universidade Veiga de Almeida. E-mail: diocaldas@ hotmail.com

${ }^{2}$ Mestranda em Direito, vinculada ao Programa de Pós-Graduação em Direito da Universidade Veiga de Almeida

- UVA, Rio de Janeiro, (Brasil). Professora da Universidade Veiga de Almeida. E-mail rgranha@globo.com
} 


\section{INTRODUÇÃO}

A teoria do Direito, há muito, vem oscilando entre as teorias jusnaturalistas e juspositivistas, sendo comum entendê-las a partir de pressupostos interiamente distintos.

Sedimentou-se a ideia de que as teses juspositivistas superaram as jusnaturalistas, a partir do iluminismo e da afirmação do Estado Liberal ou Estado de Direito, nos séculos XVIIIXIX, rompendo com a moral e alçando um novo paradigma para o Direito, como ciência autônoma.

Termos como protagonismo judicial, ativismo, aplicação direta da constituição e a aplicação de conteúdos morais na aplicação das regras jurídicas têm ocupado o cenário jurídico em função de alterações sociais significativas. No entanto, a forma de manejar estes instrumentos tem sido alvo de grandes discussões e críticas, seja pela aplicação da norma nos moldes juspositivas, seja pelo Poder Judiciário em julgamentos que correspondem a verdadeiras criações legislativas.

Inicialmente, abordaremos a tensão entre constitucionalismo e democracia, alvo de diversas discussões, não raro, amparadas pela dificuldade de delimitação de conceitos primários.

Em seguida, dimensionamos a ascensão do Poder Judiciário e o esvazimento das funcões legislativas que, na prática, alteraram os anseios preconizados pelo Estado Moderno na sua origem.

Por fim, ressaltamos a importância e os elementos ensejadores da recontrução neoconstitucionalista do Direito, sendo o pós-positivismo seu principal marco filosófico.

Diante disso, necessário se faz identificar teorias e teses jusnaturalistas, juspositivistas, antipositivistas e pós-positivistas, no intuito de contribuir para melhor compreensão do tema e no sentido de demonstrar que o jusnaturalismo e o positivismo jurídico compartilham de importantes pressupostos de um único paradigma jurídico na concretização do fenômeno denominado constitucionalismo moderno.

Este estudo pretende, inicialmente, estabelecer a relação entre jusnaturalismo, juspositivismo, pós-positivismo e neoconstitucionalismo, a fim de justificar a busca pelos elementos cada vez mais subjetivos e, ao mesmo tempo, racionais das decisões judiciais.

Para tanto, relevante será verificar se as normas jurídicas são dados prévios e seus conteúdos correspondem a conceitos fechados ou imutáveis ou se estão sempre abertas para possíveis e novas significações, formando um círculo hermenêutico dialético, bem como 
discutir alguns conceitos e parâmetros teóricos sobre a transição entre jusnaturalismo e juspositivismo, para assim, contribuir com o amadurecimento técnico e a consolidação da função judiciária, localizada no centro das atenções do Estado.

\section{TENSÃO ENTRE CONSTITUCIONALISMO E DEMOCRACIA}

A atuação jurídica tradicional é baseada no formalismo e no positivismo, demonstrando certa incapacidade em oferecer soluções satisfatórias e eficientes às atuais necessidades decorrentes dos novos tipos de conflitos sociais.

Como consequência, essas demandas são capazes de gerar novas práticas e reflexões com um diferente padrão ético, político e ideológico, reforçando a necessidade da construção de novas perspectivas mais críticas e, ao mesmo tempo, que agreguem valores humanos universais.

\subsection{As Armadilhas do Positivismo Jurídico}

Inicialmente, cumpre referenciar, como alerta Bobbio (1988. p. 25), que, a partir do final do século XVIII, o termo positivismo jurídico não deriva da expressão positivismo filosófico, apesar da ligação ideológica entre os dois movimentos. Entretanto, dois paradigmas marcaram a teoria e a filosofia do direito ao longo da história: o jusnaturalismo, relacionado ao direito natural; e o juspositivismo, ligado ao direito positivo.

O constitucionalismo é concebido como uma superação em sentido antipositivista do próprio positivismo, reconhecidamente fracassado a partir da Segunda Guerra Mundial, favorecendo o resgate ao jusnaturalismo. Para melhor compreensão do tema, serão abordados, a seguir, alguns conceitos e parâmetros teóricos sobre a transição entre jusnaturalismo e juspositivismo.

O principal conflito entre juspositivistas e jusnaturalistas traz relação íntima com a antinomia entre o Direito e a Moral.

A doutrina da escola do direito natural (ou jusnaturalismo) prescreve que todos os homens, indistintamente, têm por natureza (independente de sua vontade ou da vontade dos outros) certos direitos fundamentais, como direito à vida, à saúde, à segurança e à felicidade, e que o Estado os deve proteger. As leis no jusnaturalismo precedem à formação do grupo social 
e são reconhecidas pela racionalidade, contendo suas bases estão nas Declarações dis Direitos dos Estados Unidos da América do Norte e, na França, a partir de 1789.

Segundo Ross (2007. p. 268), há, pelo menos, três modelos do Direito Natural: o primeiro mítico ou mitológico (desde a antiguidade clássica - por volta de 700 a. C.), consagrado nos pensamentos de grandes filósofos como Platão e Aristóteles, que buscavam a existência de uma ordem cósmica absoluta, eternal e imutável.

Em seguida, na idade média, por uma perspectiva teológica, a noção panteísta ${ }^{3}$ de uma razão divina e universal, foi substituída pelo Deus cristão, fundamento de toda a existência e criador de todas as coisas. Pelos olhos de Santo Agostinho, a ideia se adequou bem à crença católica na existência do plano divino, no contraste entre o céu e o inferno, a vida mundana, secular. Neste período houve intensa produção de textos sagrados que passaram a representar a fonte da vontade de Deus, e por consequência, das leis naturais.

No terceiro estágio do jusnaturalismo, a fonte do Direito Natural passa a ser a razão subjetiva do homem. Foi conhecido por seu modelo racionalista, inaugurado por Descartes (método cartesiano) e ratificado por Kant, que recebe a influência da física de Isaac Newton, em especial, a Lei da Inércia ${ }^{4}$. Esta fórmula seriam inaplicáveis às vontades humanas, visto que são dotadas de razão e autonomia. Na obra A Crítica a Razão Pura, Kant (2010. p. 79-80) consagra o conceito de impertarivos categóricos, de modo que "todo homem deve agir de tal modo que sua ação possa ser convertida em uma lei universal da humanidade".

O agir moral de Kant (2010. p. 87) se traduz no cumprimento do dever como um "ato de escolha autônoma do homem racional", e distingue a moral do direito, enquanto o agir moral será próprio da razão humana. O homem passa a ser considerado, portanto, livre, conforme a sua razão.

O ponto de interceção entre todas estas etapas ou modelos se baseia na crença e no anseio de uma fundamentação última e absoluta como fonte eterna de justificação das normas do Direito Natural, afastando-o por completo de qualquer vertente científica.

Entretanto, a relação entre causa e efeito, aliada à racionalidade de Kant, que separa Direito da Moral, passou a enaltecer uma sociedade pautada por princípios universais extraídos da própria razão humana, colocando a filosofia do direito no plano de uma disciplina autônima.

\footnotetext{
${ }^{3}$ Doutrina filosófica caracterizada por uma extrema aproximação ou identificação total entre Deus e o universo, concebidos como realidades conexas ou como uma única realidade integrada

${ }^{4}$ Um corpo em repouso somente entrará em movimento em decorrência de uma força externa que o retire da inércia. Da mesma forma deve incidir a força externa que o faça paralizar.
} 
Neste contexto de mudanças, o direito natural passa a ser cientificamente repensado como um sistema jurídico racional, configurando um conjunto de direitos subjetivos, inerentes aos indivíduos e cidadãos, deduzido da própria natureza humana.

O Direito positivo consiste, inicialmente, no conjunto de direitos subjetivos, atriuídos aos indivídos e cidadãos, mas decorrente das relações fáticas.

O processo científico e de racionalização do Direito abriu os caminhos para o surgimento do positivismo, a partir do século XIX, propondo a superação do jusnaturalismo. Positivismo jurídico é um modelo pelo qual reconhece como direito qualquer conjunto de normas postas ou produzidas por quem está autorizado a produzi-las, independentemente de seus conteúdos ou eventual injustiças (2000. p. 115). Kelsen (2000. p. 248.) defende que o conteúdo das normas é sempre válido, sendo este, o elemento essencial do positivismo.

O jusnaturalismo não pressupõe a existência de princípios universais, imutáveis e hierarquicamente superiores ao Direito Positivo, mas uma relação de subordinação do Direito Positivo à Moral, cujos valores são universais e imutáveis, deduzidos dos princípios do Direito Natural.

O juspositivismo acusou o jusnaturalismo de um expediente arbitrário e subjetivista porque deriva e depende de uma ordem moral, que é absoluta e universal. Para os positivistas, a proposta do jusnaturalismo não passaria de uma ilusão porque carece de critérios racionais, capazes de determinar a validade ou a existência de valores absolutos (NINO, 2010. p. 23). O jusnaturalismo tem base nas teorias metafísicas, cujos valores são oriundos do cosmo ou de alguma divindade, de crenças e da pura razão, sempre na contingência de fatores históricos e culturais. O juspositivismo invoca alicerces científicos e nega a existência de um Direito Natural, inclusive acerca da existência de duas ordens jurídicas sobrepostas. Sustenta que o Estado, por meio do Poder Legislativo, é o únco que pode criar o Direito.

A fim de negar o jusnaturalismo, os positivistas adotam a radical separação entre Direito e Moral, para alcançarem os ideais de ordem, previsibilidade e segurança necessários à uma sociedade civilizada.

Uma das acusações mais contundentes ao jusnaturalismo foi elaborada pelo filósofo escandinavo Alf Ross (2000. p. 305):

Um forte argumento em favor do ponto de vista de que as doutrinas jusnaturalistas são construções arbitrárias e subjetivas é que a evidência não pode ser um critério de verdade. O que queremos dizer ao chamar uma proposição de verdadeira é, obviamente, diferente do fato psicológico de que a asserção da proposição seja acompanhada por um sentimento de certeza (...). É certo que um sentimento de evidência acompanha muitas asserções verdadeiras, mas não há razão alguma para 
que o mesmo sentimento não esteja também associado a erros e falácias. A sólida crença na verdade de uma proposição necessita estar sempre justificada e jamais pode ser sua própria justificação.

Há uma grande variedade de modelos juspositivos na doutrina. Struchiner (2005. p. 43) aponta quarto teses juspositivas: ceticismo ético, positivismo ideológico, formalismo jurídico e positivismo conceitual.

O ceticismo ético foi elaborado a partir de seguinte proposição: ou não existem princípios morais e de justiça universalmente válidos ou, mesmo que existam, não podem ser conhecidos pela razão humana. Como observa Nino (2010. p. 25-29), não são todos os positivistas que aderem à posição cética e por isso essa não pode ser a tese que diferencia o positivismo jurídico. Até mesmo autores como Alf Ross e Hans Kelsen, influenciados por concepções filosóficas empiristas e pelos postulados do positivismo lógico, adotaram uma postura cética em relação à possibilidade de se justificar racionalmente a verdade ou falsidade de juízos morais (ROSS, 2000. p. 21).

Os positivistas ideológicos, etiqueta utilizada por Norberto Bobbio (1988. p. 54), sustentam que o conteúdo das normas do direito positivo tem validade ou força moral obrigatória, ou seja, os sujeitos jurídicos e os juízes têm o dever moral de obedecer ao direito positivo, independentemente do seu conteúdo. Estes pensadores realizam uma fusão entre uma tese descritiva (a qual descreve um direito válido), e uma tese prescritiva do dever moral de obediência ao direito (NINO, 1999. p.32). Os positivistas normativos sustentam que o direito válido é automaticamente justo e que os juízes devem julgar de acordo com um único princípio moral, qual seja, o que determina a observância do direito vigente, através do slogan Gesetz ist Gesetz (A Lei é a Lei), que significa que toda ordem jurídica é direito e, como tal, quaisquer que sejam seu espírito e suas tendências, deve ser obedecido" (ROSS, 2001. p. 22).

A crítica mais contundente para o positivismo ideológico repousa no argumento que defende a possibilidade de legitimação de qualquer regime de força, como por exemplo, o nazismo.

O formalismo jurídico considera que o ordenamento é independente e capaz de, per si, oferecer uma única solução correta para cada caso. Há, assim, uma grande sintonia entre o formalismo jurídico caminha e o positivismo ideológico, sendo que este, determina que os juízes devem aplicar e as pessoas devem obedecer ao direito vigente em todas as circunstâncias. Diversas críticas invocam a impossibilidade da autossuficiência do direito e a inevitável necessidade de se recorrer, em certos casos, a critérios que estão para além do direito. 
É comum que os próprios positivistas de renome não se enquadrem nos modelos classificatórios apresentados acima, entretanto existe uma tese que os une e os identifica. Tratase do positivismo conceitual, cujo traço fundamental descreve o direito sem que necessariamente exista um comprometimento valorativo com o conteúdo das normas jurídicas. A essência do positivismo, simplesmente, estabelece o Direito em uma determinada sociedade. É um sistema de normas justo ou injusto, mas eminentemente jurídico na sua essência.

Os positivistas consideram o direito como um artefato criado, o resultado de uma escolha, convenção, ou de práticas sociais comuns. As regras jurídicas válidas são identificadas de acordo com um critério de fonte e não de mérito e o direito é fruto de regras constitutivas de instituições, produzidas e criadas pelas próprias (HART, 2009. p. 65-66).

Em que pese as diversas nuances teóricas elaboradas pelo positivismo, todas comungam das mesmas bases paradigmáticas. O método mais expressivo utilizado no positivismo é o da subsunção, do silogismo, que decorre da obtenção de uma conclusão por intermédio de uma dedução lógica, em que a premissa maior (fato), encadeada a premissa menor (norma), conduz a uma conclusão lógica.

Importante ressaltar, do método subsuntivo escapam os caos difíceis, dando azo à mera discricionariedade pelo juiz. Com a sociedade plural de hoje, o positivismo perde força e prestígio na vivência do método subsuntivo. Para sua plena e satisfatória aplicação, a sociedade deveria ser capaz de compartilhar do mesmo plano de fundo, os mesmos valores, a mesma ética, moral, religião e ideologia, elementos cada vez mais distantes da realidade contemporânea.

Ao longo do século XX predominou a cultura jurídica pós-positivista. As soluções dos problemas jurídicos não estavam mais à disposição de fórmulas pré-prontas na norma; a norma deixou de resolver as situações por si, porque o Direito não mais se bastava em si mesmo. O Juiz passou a buscar soluções na filosofia moral, em valores relevantes da sociedade, na filosofia política, estabelendo os limites da legitimidade democracrática, nas ciências aplicadas, na economia e na psicologia.

\subsection{Constitucionalismo e a Nova Hermenêutica Constitucional}

A separação entre o direito e a moral é repensada pelos teóricos do pós-positivismo e a célula principal dos princípios passou a ser o da dignidade humana, bem como dos valores morais incorporados no direito. 
A significativa mudança de paradigmas ocorreu na passagem da Constituição para o centro do Sistema Jurídico, fato que ocorreu após a 2 Grande Guerra e, no Brasil, após 1988.

O direito contemporâneo, em todo mundo, foi construído sob as bases do direito privado. Porém, no início do século XX, o cenário muda e o direito passa à esfera pública, iniciando-se uma série de tentativas de superação das desigualdades sociais e das questões econômicas. O direito privado incorpora normas de ordem pública e chega ao final do século derrotado pela ascenção da ordem jurídica interpretada e guiada pela Constituição.

Isto significou o impacto da nova principiologia do direito constitucional em todos os ramos e em múltiplos contextos, sobre a eficácia dos direitos fundamentais nas relações privadas.

Os clássicos métodos de interpretação da norma (gramatical, histórico, teleógico e sistemático) passaram a ser insuficientes para a aplicação segura na obtenção do significado presente no texto normativo. As teses pós-positivistas acusam o modelo positivista de irracionalidade, uma vez que este modelo valida o Direito através de conceitos unívocos ancorados e reconhecidos por uma autoridade.

O pós-positivismo reconhece que, ao lados das regras, existem normas jurídicas abertas que teriam um grau elevado de imprecisão, de modo a permitirem mais de um significado e interpretação para o caso. Neste contexto, surge, a partir de Hart, a distinção entre os casos fáceis e casos difíceis (HART, 2009. p. 45-50). Enquanto para os casos fáceis a regra jurídica pertence a um conceito fechado (a subjunção do fato à norma), os casos difíceis não se ajustam a um significado de regras hermético, deixando de existir uma regra única e específica.

A sociedade contemporânea passou a atribuir significados diversos aos fenômenos apresentados nos contextos históricos e culturais, no âmbito do horizonte de cada um e no interior de cada mundo da vida, conforme Habermas (2004. p. 320)

\footnotetext{
O mundo da vida em que cada um de nós está inserido nos é, desde a mais tenra idade, apresentado e apreendido em meio à linguagem que permeia os mais variados jogos de linguagem, em que somos permanentemente imersos pelos nossos pais, familiars, amigos, instituições como escolas, igurejas, empresas, artes, ciências, etc. Os jogos da linguagem, assim, constituem os variados contextos linguísticos (cultura) pelos quais e nos quais os homens fizeram uso da linguagem.
}

Não é mais possível sustentar o Direito como um fenômeno de conhecimento descritivo, neutro e objetivo ou como um simples fato social. O giro hermenêutico de viés pragmático demonstra a interpretação na norma hoje fundada em horizontes, aparentemente distintos, em que o intérprete não permaneça preso aos seus próprios pré-conceitos. 
O senso de adequabilidade não pressupõe um método específico para o intérprete, mas seleciona dados relevantes ao caso concreto, observando sempre a matéria fornecida pelas partes, para, assim, aplicar o princípio que se revele de forma mais adequada para o caso.

Na segunda metade século XX houve um (breve) resgate do jusnaturalismo, motivado em grande parte pelos regimes totalitários, em especial durante o julgamento do Nuremberg, ocasião em que foram utilizados pelos acusados argumentos justificadores das atitudes nazistas, no sentido da obediência incondicional à Lei.

Konrad Hesse (1991. p. 6-10) foi fundamental na compreensão da influência da realidade para a determinação do conteúdo constitucional. Defende o autor que "as normas constitucionais não podem ser interpretadas no campo da abstração". Em contrapartida, a interpretação constitucional não bastou conter somente traços da realidade, diante de seu poder regulador.

Hesse (1991. p. 24) considera a Constituição em termos sociológicos, cujo elemento essencial é a normatividade. Com isso, traduz a ideia de fatores reais de poder extraídos da própria sociedade, que a Constituição propõe regular. A realidade social, portanto, é capaz de influenciar no significado das normas constitucionais, condicionando-o à própria realidade e se vinculando ao contexto histórico em que está inserida.

O autor sustenta, inclusive, que a Constituição está apta às “discussões abertas”; deve ser dotada de "amplitude material e indeterminação", porque "a vida que ela quer ordenar, é uma vida histórica" (HESSE, 1991. p. 38-41).

Para Frederik Müller (MÜLLER apud SOUZA NETO, 2014. p. 50), apesar de a interpretação constitucional ter fundamental relavância, é apenas uma etapa preliminar deste processo de concretização, eis que por meio das interpretações tradicionais, merece ser adaptada e complementada com princípios constitucionais de interpretação.

Conforme conclui Cláudio Pereira de Souza Neto (2014, p. 48), pretendeu Müller, portanto, estabelecer um processo de racionalização de interpretação constitucional, utilizandose de critérios metodológicos (sobre o qual demonstra grande preocupação) no sentido de minimizar os subjetivismos e a discricionariedades, para não dizer arbitrariedade, do intérpretejuiz. 


\section{A ASCENSÃO DO PODER JUDICIÁRIO}

De acordo com a nova ordem jurídica, pode-se considerar que as raízes do positivismo jurídico também se encontram vinculadas à formação do Estado Moderno, o qual passou a concentrar todos os poderes, em especial o do processo criativo do direito, trazendo para si o monopólio da produção normativa, que recai sobre o princípio da legalidade, inerente ao Estado de Direito.

Antes da criação do Estado moderno, o juiz tinha a absoluta liberdade na determinação da norma, podendo aplicá-la de acordo com os costumes, permanecendo vinculado tão somente à aplicação das normas emanadas do órgão legislativo.

\subsection{Protagonismo Judicial e a Erosão do Poder Legislativo}

O Estado moderno nasce de uma "contínua e progressiva erosão do poder absoluto do rei; da "ruptura revolucionária" (no século XVII, na Inglaterra, e XVIII, na França). Assim preleciona Bobbio (1995. p. 15) sobre a questão:

Racionalmente, o Estado Liberal é justificado como o resultado de um acordo entre indivíduos inicialmente livres que convencionam estabelecer os vínculos estritamente necessários a uma convivência pacífica e duradoura.

Conforme já mencionado, o que une a doutrina dos direitos do homem e o Estado Moderno contratual é a concepção individualista da sociedade, que pressupõe, primeiro, a existência do indivíduo considerado na sua singularidade (necessidades e interesses) e, em seguida, sua assunção às leis da natureza; segundo, a sociedade.

Todo este movimento representou uma revolução no pensamento político dominado pelo organicismo, na medida em que subverteu as relações entre indivíduo e sociedade. Considera Bobbio (1995. p. 38) que a sociedade passou a ser um corpo artificial criado por indivíduos à sua imagem e semelhança, para a satisfação de seus interesses e o mais amplo exercício de seus direitos.

A Revolução Francesa antecipou a tensão entre juízes e legisladores, e o Estado liberal eliminou poderes intermediários, com o objetivo de concentrar o poder, antes pleno e ilimitado. Assim, "lançou mão do dogma da onipotência do legislador, cujas codificações elaboradas representam o triunfo celebrado pelo iluminismo e pelo liberalismo”. (BOBBIO, 1988. p. 38) 
Com isso, deslocou-se para o legislador a tarefa de impor normas iguais para todos, representando uma garantia dos cidadãos contra as arbitrariedades decorrentes da liberdade do juiz de aplicar as normas da forma que mais lhe conviesse na solução de litígios.

$\mathrm{O}$ século XX foi marcado por regimes totalitários que ensejaram, a partir do segundo pós-guerra, a difusão de novos pensamentos e textos constitucionais, consolidando o denominado Estado constitucional de direito, que se contrapos ao monopólio da produção jurídica do Estado Moderno. Ferrajolli (2000, p. 872) aponta as essenciais características acerca da estrutura normativa do Estado Constitucional:

(a) por la pertenencia de la normas vigentes a niveles diversos y jerárquicamente ordenados, cada uno de los cuales se configura como normativo respecto del inferior y como fáctico en la relación com el superior; b) por la incorporación a las normas superiores de obligaciones y prohibiciones que disciplinan la producción de las normas inferiores y cuya observancia es condición de la efectividad de las primeras y de la validez de las segundas; c) por las antinomias producidas por las violaciones de las normas superiores por parte de las inferiores y por la simultánea vigencia de unas, aun cuando inefectivas, y de las otras, no obstante su invalidez; d) por la consiguinte ilegitimidad juridica que en alguna medida afecta siempre a los poderes normativos, legislativo y judicial y que es tanto mayor cuanto más amplia pero inefectiva resulte la incorporación limitativa de los deberes a los niveles más altos del ordenamiento". 5

Conforme aponta Karam (2006, p. 183):

“As Constituições tornam a norma hierarquicamente mais elevada dos sistemas jurídicos contemporâneos não apenas do ponto de vista formal, mas, também, do ponto de vista substancial, na medida em que passam a impor ao legislador, além do respeito lógico-formal aos procedimentos estabelecidos, o desenvolvimento e, sobretudo, a aplicação dos conteúdos."

Todas as mudanças na cultura jurídica atual provocaram a consolidação da constitucionalização de diversos ordenamentos jurídicos, ocupando novo espaço para os debates, onde os dispositivos constitucionais passaram a influenciar diretamente em todos os ramos do direito.

O constitucionalismo contemporâneo não chegou a constituir um rompimento radical com o constitucionalismo moderno do Estado Liberal, pois apresenta muito mais um aspecto de continuidade do que de oposição.

\footnotetext{
${ }^{5}$ a) a adesão das regras existentes e que pertencem aos variados níveis hierarquicamente ordenados, configurados como uma relação normativa factual inferior em relação à superior buscando a coerência de seus conteúdos com os princípios constitucionais; b) a incorporação aos padrões mais elevados de obrigações e proibições que regulam a produção de normas inferiores, cujo cumprimento é condição da eficácia e de validade; c) as contradições orientadas por violações das regras, considerem as normas ineficazes ou nulas, preconizando a harmonia com os princípios constitucionais; d) a subordinação das leis aos princípios constitucionais, que introduzem uma dimensão substancial não só no que diz respeito às condições de validade das normas, mas, inclusive, no que se refere à natureza da própria na medida em que, ao representar um limite ao poder da maioria.
} 
Möller (2011. p. 24) descreve com clareza:

A lei passa a ser, portanto, o instrumento para aplicar e interpreter a constituição, limitar o poder e manifestar a vontade popular. Este movimento, denominado legicentrismo, representava perfeitamente os ideais modernos da segurança e igualdade.

A crise enfrentada pelo direito, a partir da decadência do modelo formalista-liberal, trouxe a necessidade de um resgate dos ideais filosóficos, como reafirmação de valores relevantes aos quais o direito deve servir. Esta concepção visualiza o direito como um núcleo de resistência social ante o poder e no sentido da manutenção de valores não dependentes de decisões políticas.

Como consequência, inevitável a readequação das atividades do poderes, em especial do Poder Judiciário que passa a ocupar uma posição de destaque e afirmação do sentimento constitucional perante a sociedade e as instituições.

Ensina Möller (2011.p. 26) que:

a ideologia neoconstitucionalista se aparesenta como o movimento jurídico de oposição à lógica do Estado decimonômic, onde imperava o legalismo, o culto à lei e a concepção de atividade judicial como atividade mecânica de aplicação da lei.

A prevalência do poder Judiciário sobre os demais poderes, entretanto, não traz entendimentos pacíficos. O Protagonismo Judicial é alvo de fervorosas críticas, em especial nos campos da filosofia e da sociologia, por razões advindas do crescimento do uso da hermenêutica filosófica no direito.

Como salienta Lenio Streck, "interpretar é compreender. E compreender é aplicar. A hermenêutica não é mais metodológica. Não mais interpretamos para compreender, mas sim, compreendemos para interpreter (...) hermenêutica é, agora, produtiva" (STRECK, 2015, p. $83)$.

Judicialização, em linhas gerais, significa a transferência de poder das instâncias políticas tradicionais para o poder judiciário, esvaziando a prevalência dos poderes Legislativo e Executivo, ocorrido durante as décadas passadas.

Defende, ainda, Lenio Streck (STRECK, 2015, p. 84) que a hermenêntuca não deveria mais ser uma teoria das ciências humanas, e nem uma expressão da teoria da subjetividade. Com isso, não mais se poderia repetir o erro e a confusão que as teorias metafísicas faziam entre ser e ente . $^{6}$

\footnotetext{
${ }^{6}$ Lenio Streck, neste aspecto da hermenêutica (ir)racional, baseiou-se em Heidegger, em especial na questão entre o ser e o ente, que significa, em breves linhas, que o homem seria o ente aberto ao ser, que, por isso, é o único ente que pode compreender o ser. De nenhum modo é um ente já fixo tal como o sentido comum se representa o ser da
} 
A aplicação da filosofia no direito para uma interpretação filosófica expressa um exercício de pensamentos e conceitos jurídicos fundamentais que conduz o intérprete a problematizar seus limites e a comprometer seus parâmetros teóricos. O jurista não fabrica o seu objeto de conhecimento e o modelo extremamente teórico de abordagem, gera o engessamento do mundo prático. Ou seja, o contexto empírico das relações humanas, locus do direito, está além do positivismo.

A política vive uma relação difícil com a sociedade civil. O desencanto contribui cada vez mais para a ascenção do judiciário, o que, de acordo com, Luiz Roberto Barroso, dá azo à uma forma própria de julgamento com base na racionalidade. Tal fato merece atenção e cautela, eis que o significado prático de "racionalidade jurídica" tende a variar de acordo com o pensamento de cada magistrado, livre e convencido de que faz o seu melhor, mas nem sempre em harmonia com os preceitos fundamentais.

Este fenômeno, de acordo com Daniel Sarmento, "pode provocar uma certa anarquia metodológica" (SARMENTO, 2006. p. 167-189). Muitas vezes a falta de critérios pela realização de normas pelo Poder Judiciário podem comprometer valores muito caros ao Estado Democrático de Direito.

A judicialização decorre do fato do legislativo esquivar-se das decisões politicamente difícies, e no Brasil, o sistema de controle de constitucionalidade potencializa esse fenômeno.

O ativismo judicial difere da judicialização, significando uma attitude, uma disposição de expandir o papel do judiciário a situações não previstas. Ou seja, é uma attitude (e não um fato) que reage à omissão e ao descrédito da política.

\section{A RECONSTRUÇÃO NEOCONSTITUCIONASTA DO DIREITO}

O constitucionalismo é definido por Canotilho como "a ideologia que ergue o princípio do governo limitado, indispensável à garantia dos direitos, em dimensão estruturante da organização político-social de uma comunidade" (CANOTILHO, 2002. p. 186).

O neoconstitucionalismo corresponde a uma evolução natural do constitucionalismo, na busca de garantir e concretizar os direitos fundamentais.

pedra ou de uma mesa. Ele se caracteriza por uma relação permanente de instabilidade que mantém em si mesmo. O homem é a porta de entrada do ser. 


\subsection{Pós-Positivismo como Marco filosófico do Neoconstitucionalismo}

A essência da reconstução neoconstitucionalista do Direito moderno repousa na superação da racionalidade subsuntiva, cedendo espaço para a racionalidade discursiva e associada à “dimensão retórica das decisões judiciais". (OLIVEIRA, 2007. p. 115)

O modelo de interpretação tradicional da constituição é específico e se socorre de elementos relevantes como a supremacia constitucional, a unidade, a razoabilidade, a proporcionalidade e a efetividade. E, neste sistema, sempre existiu um papel típico para a norma: enquanto o intérprete desempenha uma função técnica; os fatos existem só para que o juiz identifique e enquadre o fato à norma. Trata-se de um racioncínio silogístico, como já mencionado.

Com a sociedade multifacetária, essa interpretação tradicional não consegue mais alcancar as variáveis do sistema social. Com a intervenção do judiciário nas relações de naureza eminentemente política, inclusive legais, o juiz passa a criar a norma quando decide o que pretende ou o não pretende privilegiar, além disso, impõe uma decisão política que não pertence à sua função originária.

A argumentacao jurídica é fundamental para os casos difícies, eis que neste ambiente novo de interpretação constitucional, a norma auxilia a indicar o melhor caminho. Ela vai ser concretizada no caso concreto. Se a solução não está na norma, recorrem os Tribunais a fatos que, certamente, contém parte da solução. O Juiz hoje é um coparticipante do processo de criação do direito, constatação que traz grandes preocupações para o sistema democrático de direitos. A rigor, carece o Poder Judiciário, afastar ou desmudar leis elaboradas por representantes escolhidos pela vontade popular. É o que se chama de desafio contramajoritário.

Preleciona Daniel Sarmento (2006. p. 144):

"É o lado do decisionismo e do "oba-oba". Acontece que muitos juízes, deslumbrados
diante dos princípios e da possibilidade de através deles, buscarem a justiça - ou que
entendem por justiça -, passaram a negligenciar no seu dever de fundamentar
racionalmente os seus julgamentos. Esta "euforia" com os princípios abriu um espaço
muito maior para o decisionismo judicial. Um decisionismo travestido sob as vestes
do politicamente correto, orgulhoso com seus jargões grandiloquentes e com a sua
retórica inflamada, mas sempre um decisionismo. Os princípios constitucionais, neste
quadro, converteram-se em verdadeiras "varinhas de condão": com eles, o julgador de
plantão consegue fazer quase tudo o que quiser. Esta prática é profundamente danosa
a valores extremamente caros ao Estado Democrático de Direito. Ela é prejudicial à
democracia, porque permite que juízes não eleitos imponham a suas preferências e
valores aos jurisdicionados, muitas vezes passando por cima de deliberações do
legislador. Ela compromete a separação dos poderes, porque dilui a fronteira entre as
funções judiciais e legislativas. E ela atenta contra a segurança jurídica, porque torna 
o direito muito menos previsível, fazendo-o dependente das idiossincrasias do juiz de plantão, e prejudicando com isso a capacidade do cidadão de planejar a própria vida com antecedência, de acordo com o conhecimento prévio do ordenamento jurídico".

Por outro lado, defende Barroso (2006. p. 377):

\begin{abstract}
Questiona a doutrina se a política majoritária conduzirda por representantes eleitos, é um componente vital para a democracia. Mas a democracia é muito mais do que a mera expressão numérica de maior quantidade de votos. Para muito além desse aspecto, ela possui uma dimensão substantiva, que abrange a preservação de valores e direitos fundamentais.
\end{abstract}

O grande vilão no ativismo judicial parece ser a "nova" interpretação constitucional utilizada pelo magistrado, aparentemente, sem contenção. Em que medida "a normatividade de princípios, a ponderação de valores e a teoria da argumentação” (STRECK, 2015. p. 47-53), defendida por autores como Lenio Streck, podem e conseguem limitar a atuação judicial?

Tudo isso visa a conter a discricionariedade judicial, demarcando parâmetros para a ponderação de valores e interesses. As constituições contemporâneas apresentam um número significativo de direitos fundamentais positivados. Em muitos casos, anunciam preceitos disciplinadores de sua aplicação, com o escopo de especificar tutelas de direitos fundamentais. Isto leva o magistrado a julgamentos completamente diferentes àqueles de um passado recente. O juiz de hoje é coparticipante da criação do direito.

O pós-positivismo traz a releitura que entrelaça o jusnaturalismo e juspositivismo, restando em segundo plano o comando normativo desvinculado da moral. O positivismo desprezava as categorias axiológicas do jusnaturalismo, enquanto o pós-positivismo passa a ser reconhecido como uma terceira via entre as ideias positivistas e jusnaturalistas, fazendo emergir o conteúdo moral na estrutura do direito.

\title{
3.2 Aspectos do Constitucionalismo no Brasil
}

O Brasil tem sido marcado na sua história pelas peculiaridades de um nascedouro colonial, fato que não pode ser descartado para melhor compreensão do constitucionalismo atual. Para tanto, ainda que de forma suscinta, vale destacar as diversas etapas da teoria constitucional no Brasil, especialmente, ao que rerefere à teoria da efetividade, conforme propõe Christian Lynch e José Vicente Mendonça (2016). Para os autores, há três importantes teses da doutrina da efetividade a despeito da história constitucional:

Primeiro a que haveria uma tradição constitucional brasileira, que cumpria ser combatida; segundo, que essa tradição teria inefetividade como marca; terceiro, que 
a referida inefetividade se originava de um vício das elites brasileiras, sua "insinceridade normativa".

Acescentam, ainda:

\begin{abstract}
A leitura de obras paradigmáticas do novo constitucionalismo sugere que, ao contrário do europeu, o neoconstitucionalismo brasileiro - em particular, sua teoria de base, a doutrina da efetividade -, construiu-se deliberadamente contra nossa história constitucional. (...) Deste o final dos anos noventa, o direito constitucional brasileiro foi objeto de extraordinária ascensão, tendo desbancado a hegemonia da processualística e do direito civil. Para tanto, concorreram o modelo da Constituição de 1988, disciplinando a quase totalidade da vida social; e a outorga, ao Poder Judiciário, do papel de velar pela constituição (2016).
\end{abstract}

O sistema adotado foi o do constitucionalismo dirigente, que "enuncia programas, motivos, meios e fins, vinculando a atuação do Estado, através de pautas formais e materiais, que sujeitam a conduta de cada um dos três poderes" (VEIRA, 2007. p. 86), norteados pelas propostas reformadoras do socialismo democrático (esquerda nacional). Os ideais eram pautados na reconhecida necessidade de transformação social, que deveria ser alcançada por meio de recursos constitucionais democráticos.

O expoente deste pensamento foi Raymundo Faoro, em especial na obra Assembléia Constituinte: a legitimidade recuperada. Afirma o autor, que as constituições brasileiras não foram capazes de cumprir sua função democrática e somente com o esquecimentodo passado seria possível vencer o "monstro autoritário" (FAORO, 1981. p. 94-95) controlado pelas elites. O Brasil não era, de fato, um Estado Brasileiro.

Ao ser instaurado o ambiente democrático, passou-se a compreender que o papel da Constituição de 1988 seria o de desenvolver um ambiente capaz de garantir a efetivação das expectativas contidas nas entrelinhas do texto, ou seja, ao mesmo tempo em que se reconhecia sua dimensão garantista, reconhecia-se sua característica dirigente.

Parece temeroso negar que a constituição brasileira é menos efetiva comparada aos “países vistos como modelos de "bom” constitucionalismo" (LYNCH e MENDONÇA, 2016).

O conceito material de legitimidade constitucional de uma constituição dirigente busca apurar a vinculação entre Estado e sociedade, através da prioridade de temas que versam sobre a estrutura das normas programáticas, o grau e a forma desta vinculação.

Conforme preleciona Claudio Pereira de Souza Neto (2014, p. 53-55), o ponto central visa apurar em que medida o "conteúdo material fixado no programa constitucional é determinante para a atividade legislativa, definindo o próprio teor das decisões políticas tomadas pelas gerações futuras”. 
A ideia de Constituição dirigente no Brasil permanece ao lado de outra teoria que sofreu influência direta para a sua compreensão, denominada de constitucionalismo da efetividade.

Com isso, uma das preocupações centrais do pensamento constitucional brasileiro passou a ser no sentido da valorização do desenvolvimento de uma "dogmática da efetividade" (LYNCH e MENDONÇA, 2016), com foco no Poder Judiciário.

Não se pode descartar a relevância de todo o conteúdo constitucional anterior à Constituição de 1988. Por certo, "há, na atual constituição, comandos herdados de constituições anteriores, e que, naturalmente, já foram interpretados no passado" (LYNCH e MENDONÇA, 2016).

Atualmente, apesar de o Brasil ainda não ter superado por completo o positivismo jurídico, o plano da efetividade e os seus preceitos estruturais estão inter-relacionados e tendem à uma elaboração de critérios materiais para maior sedimentação da efetividade constitucional.

Como país periférico (LYNCH, 2014. p. 28-29) que é, vive ainda a construção de sua teoria constitucional e é preciso a dedicação mais aprofundada dos escritores locais que vivenciaram todo o processo de elaboração da nossa história e, certamente, serviram de sustentáculo para a democracia constitucional, a partir de 1988.

Luis Roberto Barroso (2003. p. 329), em importante obra sobre a nova interpretação constitucional, considera que a efetividade da Constituição tornou-se uma ideia vitoriosa e incontesada, cujas normas jurídicas estão aptas a tutelar, direta e imediatamente, todas as situações que contemplam.

Neste momento de crise, parece inevitável a busca por novos paradigmas, locus ideal para o que hoje se compreende por pós-positivismo, caracterizado pela ligação entre Moral e Direito, por meio de interpretações abertas, de princípios, idealizados por uma metodologia pautada na técnica racional da argumentação jurídica.

A força normativa dos princípios é revertida de carga axiológica, abrindo espaço para significados de conteúdo moral (BARCELLOS, 2005. p. 53). Entra em cena um outro paradigma denominado neoconstitucionalismo, no qual o Brasil está inserido, e que possui uma forte ligação com a prevalência do Poder Judiciário, no sentido de projetar ideais contemporâneos e emancipatórios das atuais constituições dos países cêntricos" (LYNCH, 2014. p. 32).

Contudo, fervorosas críticas, de fundamentos democráticos, são direcionadas ao neoconstitucionalismo, por alocar o judiciário no centro da máquina decisória. No Sistema 
democrático, as decisões políticas devem ser tomadas pelo povo (seus representantes) e não por magistrados. Da mesma forma, a valorizaçao da interpretação constitucional por técnicas de ponderação em detrimento de regras, faz emergir um sentimento de insegurança jurídica causado pelo risco de se estabelecer uma espécie de anarquia metodológica.

Neste ponto, merece especial atenção, no entanto, à dosagem para a aplicação das técnicas mencionadas, a fim de evitar decisões pouco fundamentadas e tendentes à manifestações calorosas, meramente retóricas, que se distanciam dos ideais democráticos.

\section{CONCLUSÃO}

A nova relação entre o direito e a moral é decorrente das aspirações sociais, cada vez mais multifacetárias, que evoluem com um pensamento constitucional os valores universais da ética, do bom senso e da justiça.

Este trabalho pretendeu estabelecer a relação entre jusnaturalismo, juspositivismo, pós-positivismo e neoconstitucionalismo, na tentativa de se compreender e, por que não, justificar a busca pelos elementos cada vez mais subjetivos das decisões judiciais. Inegável que a previsibilidade de decisões garante o Estado e fomenta o sentimento de segurança jurídica nos indivíduos, entretanto uma sociedade democrática não se esgota nos casos conhecidos e alcançados pelas maiorias.

As questões que versam sobre moral e direito aparecem diariamente nas decisões judiciais. Segundo a ótica dos mais variados autores, admite-se que os processos decisórios podem ser criativos, ainda que importem na criação do Direito pelo juiz, mas esbarram na questão de que não parece possível racionalizar todo este processo criativo.

Independentemente do modelo teórico utilizado, no sistema jurídico há uma prévia referência normativa, em que o aplicador do Direito terá como missão encontrá-la e aplicá-la no caso concreto. O verdadeiro problema é que, ao se partir do pressuposto de que há, para o caso concreto, uma norma prévia, o significado desta norma também será previamente determinado.

Assim, pode-se concluir que esta escolha realizada pelo juiz será sempre prévia e discricionária, demonstrando o inevitável retorno às teorias do paradigma positivista.

Já nas teorias antipositivas, cujo expoente é Alexy, sua regra da proporcionalidade resolve antinomias entre princípios diante do caso concreto, mas também nos remete à um significado prévio da norma, mesmo passando, preliminarmente, pelos critérios de ponderação. 
Sempre haverá situações em que, mesmo com a aplicação da técnica da ponderação, a solução será passível de discussão, eis que o fundamento se concentra no juízo moral e ético, não só das maiorias, como também das minorias.

Buscamos demonstrar neste estudo, portanto, que as normas jurídicas talvez nunca sejam dados prévios e seus conteúdos se tornem conceitos fechados ou imutáveis. Ao revés, estão sempre abertas para possíveis e novas significações, formando um círculo hermenêutico dialético.

Como fonte inesgotável de anseios, é certo que a natureza humana permanecerá em constante mutação, tornando-se cada vez mais complexa. Por conta disso, parece fundamental desenvolver e aprimorar uma linha de estudos de técnicas jurídicas que viabilizem a comunicação entre teoria e operacionalidade, cujo objetivo principal seja efetivar o Direito na vida das pessoas, a fim de que possam se beneficiar dos progressos técnicos de elaboração jurídica.

\section{REFERÊNCIAS}

ÁVILA, Humberto. Teoria dos princípios. São Paulo: Saraiva, 2012.

BARCELlOS, Ana Paula de. Ponderação, Racionalidade e Atividade Jurisdicional. Rio de Janeiro: Renovar, 2005.

BARROSO, Luis Roberto. (Org.) Nova interpretação constitucional. Ponderação, direitos fundamentais e relações privadas. Rio de Janeiro: Renovar, 2003.

BOBBIO, Norberto. O Positivismo Jurídico. Lições sobre o Positivismo Jurídico. São Paulo: Ícone, 1995.

Liberalismo e Democracia. São Paulo: Brasiliense, 1988.

CANOTILHO, José Joaquim Gomes. Direito Constitucional e Teoria da Constituição. 5. ed. São Paulo: Editora Livraria Almedina, 2002. 
DWORKIN, Ronald. Talking rights Seriously, 1977. Cambridge: Harvard University Press, 1977.

FAORO, Raymundo. Assembléia Constituinte: a legitimidade recuperada. São Paulo: Brasiliense, 1981.

FERRAJOLLI, Derecho y razón. 4. ed. Madrid: Trotta, 2000.

HABERMAS, Verdade e justificação. Ensaios filosóficos: trad de Milton Camargo Mota. São Paulo: Loyola, 2004.

HART, Herbert L. A. O Conceito de Direito. São Paulo: Wmf Martins Fontes, 2009.

HESSE, Konrad. A Força Normativa da Constituição. São Paulo: Sergio Antonio Frabris editor, 1991.

KANT, Immanuel. Crítica a Razão Pura. 7a. Ed. Lisboa: Fundaçao Calouste Gulbenkian, 2010.

KELSEN, Hans. Teoria Geral do Direito e do Estado. São Paulo: Martins Fontes, 2000. Teoria Pura do Direito. São Paulo: Martins Fontes, 2000.

LYNCH, Christian Edward Cyril. Da Monarquia à Oligarquia: História institucional e pensamento politico brasileiro (1822-1930). São Paulo: Alameda, 2014.

e MENDONÇA, José Vicente Santos de. Por uma História Costitucional Brasileira: uma crítica pontual à doutrina da efetividade. Artigo no prelo da Revista Lua Nova, citado com autorização do autor. 2016.

MÖLLER, Max. Teoria Geral do Neoconstitucionalismo: bases teóricas do constitucionalismo contemporâneo. Rio Grande do Sul: Livraria do Advogado, 2011. 
MÜLLER apud NETO, Claudio Pereira de Souza apud MÜLLER Frederik. Direito Constitucional. Teoria, história e métodos de trabalho. Belo Horizonte: Forum, 2014.

NINO, Carlos Santiago. Introdução à Análise do Direito. São Paulo: Martins Fontes, 2010.

OLIVEIRA, Fábio Corrêa de Souza. A Constituição Dirigente Está Morta... Viva a Constituição Dirigente! In: BARROSO, Luis Roberto. (org) A Reconstrução Democrática do Direito Público no Brasil. Rio de Janeiro: Renovar, 2007.

ROSS, Alf. Direito e Justiça. São Paulo: Edipro, 2000.

SARMENTO, Daniel. Livres e Iguais. Estudos de Direito Constitucional. Rio de Janeiro: Lumen Juris, 2006.

STRECK, Lenio Luiz. O Que é Isso - Decido conforme minha consciência? Rio Grande do Sul: Livraria do Advogado, 2015.

STRUCHINER, Noel. Para falar de Regras: O Positivismo Conceitual como Cenário para uma Investigação Filosófica acerca dos Casos Difíceis do Direito. Tese apresentada ao Programa de Pós-graduação em Filosofia da PUC-Rio, em 2005.

TRINDADE, André Karam. A Filosofia No Direito: com gadamer, contra habermas, à procura de um paradigma de racionalidade a partir do qual seja possível pensar pósmetafisicamente a teoria do direito contemporâneo. Dissertação de Mestrado apresen-tada junto ao Programa de Pós-Graduação em Direito da Universidade do Vale do Rio dos Sinos (UNISINOS), para obtenção do título de Mestre em Direito Público sob a orientação do Prof. Dr. Lenio Luiz Streck. São Leopoldo, 2006. 